\title{
Contribution of Direct Obstetric Complications to Maternal Deaths in Makurdi, North-Central Nigeria.
}

\author{
Silas Ochejele ', Omeche Adama ${ }^{2}$ and Patrick H. Daru ${ }^{3}$

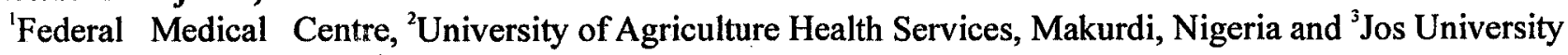 \\ Teaching Hospital, Jos, Nigeria.
}

\begin{abstract}
Context: The Federal Medical Centre Makurdi is the only tertiary health institution in Benue State. Maternal deaths are a frequent occurrence in the centre thereby necessitating this study.

Objective: To determine the maternal mortality ratio, the case fatality rate and the contribution of direct obstetric complications to these deaths.

Subjects and Methods: A four month descriptive study of obstetric service data from $1^{\text {st }}$ January to $30^{\text {th }}$ April 2004.

Results: During the study period, there were a total of 363 deliveries ( $52 \%$ unbooked, $48 \%$ booked, $20 \%$ DOC.) and 16 maternal deaths $(94 \%$ were direct) giving a maternal mortality ratio of $4,408 / 100,000$ deliveries. $14(87.5 \%)$ of the deaths were unbooked obstetric emergencies. The overall case fatality rate (CFR) was $21 \%$. The contribution of each direct obstetric complication to the direct maternal deaths was as follows: obstructed labour/ ruptured uterus (53.3\%), postpartum haemorrhage (13.35\%), puerperal sepsis (13.35\%), Eclampsia (6.68\%), induced Abortion (6.68\%). The cause- specific CFR was in this order. Ruptured uterus $100 \%$, Puerperal sepsis $100 \%$, Abortion $25 \%$, severe Preeclampsia/Eclampsia $20 \%$, Obstetric haemorrhage $12.5 \%$, obstructed labour $11.4 \%$. The caesarean section rate was $15 \%$. Facilities to provide life saving functions were lacking and staff commitment was low.

Conclusion: Urgent emergency obstetric care training of residents and provision of parenteral antibiotics, anticonvulsants, oxytocics and safe blood for transfusion is recommended.
\end{abstract}

Key Words: Maternal Mortality, Direct Obstetric Complications, Nigeria. [Trop J Obstet Gynaecol, 2005, 22: 37-38]

\section{Introduction}

Benue state is one of Nigeria's 36 states and it is situated in North-Central Nigeria. It has a population of 3.8 million people and estimated 152,000 deliveries annually. $15 \%(22,800)$ of these is expected to be complicated '. The Federal Medical centre is the only tertiary health institution in the state and it is expected to be a high quality emergency obstetric care (EmOC) facility. To improve the quality of emergency obstetric services for women who experience life- threatening complications, a base line data is required. This study was necessitated by the frequent maternal deaths in the centre and it is aimed at reducing maternal mortality with the objective of determining the maternal mortality ratio, the case fatality rate and the contribution of direct obstetric complications to these deaths.

\section{Materials and Methods}

The four months descriptive study was carried out using routine obstetric services data, from $1^{\text {st }}$ January to $30^{\text {th }}$ April 2004. Data was collected from the medical records, theatre, labour ward, postnatal ward and gynaecology wards and from the patients and their case notes. Direct observation and staff interview were also used. Working definitions of direct obstetric complication was derived from "IMPAC /WHO/ FIGO "save the mothers projects". The diagnoses of the deaths were clinical.

\section{Results}

During the study period, there were a total of 363 deliveries. $189(52 \%)$ were unbooked while the minorities $174(48 \%)$ were booked. There were 35 perinatal deaths (25 stillbirths and 10 Early neonatal deaths) giving the perinatal mortality rate of $96 / 1000$ deliveries (69 stillbirths and 28 Early neonatal deaths / 1000 deliveries respectively). There were 16 maternal deaths giving a maternal mortality ratio of 4,408 / 100,000 deliveries $.15(94 \%)$ of the deaths were direct giving a CFR of $21 \% .2(13.3 \%)$ of these deaths occurred within 24 hours of admission. $14(87.5 \%)$ of the deaths were unbooked obstetric emergencies while $1(6.3 \%)$ was booked. There were 56 caesarean sections giving the caesarean section rate of $15 \%$.

Total direct obstetric complications for the period were 71 , which constituted $20 \%$ of the deliveries. Ruptured uterus and puerperal sepsis had an unacceptably high CFR of $100 \%$ each. While the corresponding figures for abortion, severe $\mathrm{PIH} / \mathrm{Eclampsia}$, obstetric haemorrhage, obstructed labour, and ectopic pregnancy were $25 \%, 20 \%, 12.5 \%, 11.4 \%$ and $0 \%$ respectively.

Table 1 shows the contribution of each of the complications to the maternal deaths. Obstructed

Correspondence: Dr Silas Ochejele, Federal Medical Centre, Makurdi, Nigeria.E-mail: silasfriday@yahoo.com 
labour/ruptured uterus was the commonest cause of death $(53.34 \%) .100 \%$ of these had puerperal sepsis while $87.5 \%$ had postpartum haemorrhage. The only patient who died without postpartum haemorrhage had obstructed labour and died before caesarean section was done. The remaining patients died after surgery (caesarean section/laparotomy for obstructed labour/ruptured uterus respectively).

\section{Table 1:}

The contribution of each direct obstetric complication to the direct maternal deaths

\begin{tabular}{lcc}
\hline Complication & $\begin{array}{c}\text { Number of } \\
\text { maternal deaths }\end{array}$ & $\%$ \\
\hline Obstructed labour & 4 & 26.67 \\
Ruptured uterus & 4 & 26.67 \\
Puerperal sepsis & 3 & 20.00 \\
Obstetric haemorrhage & 2 & 13.33 \\
PIH/Eclampsia & 1 & 6.67 \\
Abortion & 1 & 6.67 \\
Ectopic pregnancy & 0 & 0.00 \\
Total & 15 & 100.00 \\
\hline
\end{tabular}

\section{Discussion:}

The maternal mortality ratio (MMR) in this study was $4,408 / 100,000$ deliveries. $94 \%$ of the deaths were direct and obstructed labour/ ruptured uterus accounted for majority $(53 \%)$ of these deaths. The CFR is $21 \%$ and the caesarean section rate is $15 \%$. Partograph was not used to monitor labour and there were no parenteral antibiotics, anticonvulsants or antihypertensives and intravenous fluids in the maternity. Blood was not immediately available for transfusion and no theatre nurse, anaesthetist and laboratory scientist slept in the hospital during the period. House officers were the only doctors who slept in the hospital. There was no oxygen and suction machine in the maternity for neonatal and maternal resuscitation during the period. There was no instrumental vaginal delivery during the period. There was no sphygmomanometer in the maternity. This descriptive study shows the outcome of the poor quality of services on maternal mortality. The weakness of the study design is the inability to assess the condition of

\section{References}

1. Ujah AO, Ochejele S, Jogo A, Aida A, Adama O, Heywood A et al., Emergency Obstetric Care in Benue State. A Survey of the 100 Busiest Maternities. Partnership for Transforming Health Systems, Benue State, 2003; $1-9$.

2. Paxton A, Maine D, Hijab N. Using UN process Indicators of Emergency Obstetric Services, AMDD Workbook. Questions and Answers, 2003; 7-9.

3. Adetoro OO. Maternal Mortality An 11-year survey of the University of Ilorin Teaching Hospital (UITH), Ilorin, Nigeria. Int J Obstet Gynaecol, 1987; 25: 93-98

4. Adetoro OO, Okwerekwu EE, Ogunbode O. Maternal Mortality at Ilorin, Nigeria. Trop J Obstet Gynaecol, 1988; 1: 8-21.

5. Aboyeji AP. Trends in Maternal Mortality in Ilorin, Nigeria. Trop $J$ Obstet Gynaecol, 1998; 15 (1): 15-20. the patient on admission.

The maternal mortality ratio (MMR) in this study was $4,408 / 100,000$ deliveries, this is higher than 450,280 and 532 reported from university of Ilorin Teaching Hospital $^{3.45 .}$ and 3,392 reported from Abakaliki ${ }^{{ }^{6 .}}$ It is equally higher than the national average of 800 and ratios obtained from other developing countries: Namibia 300, Ghana 540, Gambia 540 and Ethiopia 850 7. When compared with what is available in the developed countries (Sweden 2, Slovakia 3 and Spain 4 per 100,000 births), it is unacceptably high ${ }^{7}$.The contribution of direct obstetric complications to these deaths was $94 \%$. This is higher than the $78.6 \%$ and $79.3 \%$ reported from Lagos and Ilorin respectively ${ }^{8,5}$. It is also higher than the global average of $80 \%{ }^{9}$. This was due to the poor quality of EmOC services. Since these complications are treatable, these deaths would have been prevented if the quality of the services were good.

The CFR of $21 \%$ is much higher than the maximum international benchmark of $1 \%$ and the $0.84 \%, 0.43 \%$ and $0.25 \%$ reported from Morocco, Nicaragua and Srilanka respectively ${ }^{10}$. This figure is also higher than the Benue State average of $8 \%$ reported from PATHS Emoc survey'. The difference from the state figure was due to the under-reporting in the surveyed facilities and the fact that majority of the surveyed health facilities were not receiving women with complications.

The CFR from obstructed labour/ruptured uterus of $53 \%$ is higher than the global average of $8 \%$ and the $9 \%$ and $15 \%$ reported from Lagos and Ilorin respectively ${ }^{9.3 .5}$. The study shows that most of the deaths are preventable and the quality of emergency obstetric care is poor with a resulting high maternal mortality. Commitment of the policy makers and health workers to good quality services and avoidance of delay by patients when complication occurs will reduce these deaths. Maternal mortality from this study is high and preventable and this is a call for action. A criterion-based audit is recommended to study the circumstances surrounding each death.

6. Ibekwe PC, Dimejesi I. Obstetric Indices of Ebonyi State University Teaching Hospital, Abakaliki. Abstracts of the 2003 conference held at Port Harcourt. Trop J. of Obstet Gynaecol, 2003; 20, (suppl.1): 32-33.

7. Carol B. The State of the world's children 2004. UNICEF, 2003; 130- 132.

8. Agboghoroma OC, Emuveyan EE. Maternal mortality in Lagos: A Ten Year Review (1986-1995). Nig Qt J Hosp Med, 1997; 7(3): 230-233.

9. WHO. Reduction of Maternal Mortality. $A$ Joint WHO/UNFPA/UNICEF/World Bank Statement, 1999; 1.

10.Bailey PE. Averting Maternal Death and Disability. Program note: Using UN process indicators to assess needs in emergency obstetric services: Morocco, Nicaragua and Sri Lanka. Int . Gynecol Obstet, 2003; 80: 222-230. 